p-ISSN 1693-9484, $e$-ISSN : 2621-8313

Majalah Ilmiah Bahari Jogja (MIBJ)

Vol. 19 No. 1, Februari 2021

(59-69)

DOI: $10.33489 /$ mibj.v19i1.258

(C) 2021 Sekolah Tinggi Maritim Yogyakarta

\title{
STRATEGI PEMBELAJARAN KERJASAMA TIM PADA PEMASANGAN PERANCA DI PORTSIDE MODEL MOORING AND WINDLASS STIMARYO
}

\author{
Ade Chandra Kusuma ${ }^{*}$, Iswanto ${ }^{2}$ \\ ${ }^{1}$ Sekolah Tinggi Maritim Yogyakarta, Jl. Magelang KM 4.4, Yogyakarta 55284, \\ Indonesia \\ * Corresponding Author. E-mail: adepng12@gmail.com. Telp: 085292372862
}

\begin{abstract}
Abstrak
Pelaksanaan pembelajaran bermain peran dalam pemasangan peranca merupakan model pembelajaran konteks dalam proses transfer ilmu untuk mencapai kompetensi taruna Sekolah Tinggi Maritim Yogyakarta atau Stimaryo sebagai calon pekerja di kapal. Kepemimpinan dan kerjasama tim dilakukan di model mesin jangkar mooring and windlass milik STIMARYO pada Prodi Studi Nautika. Adapun tujuan dalam karya tulis ini adalah penelitian tindakan kelas dalam proses ketercapaian berupa ketuntasan dalam mencapai kompetensi minimal atau kriteria ketuntasan minimal 75. Metode pembelajaran kecakapan bahari II ini menggunakan metode role play atau bermain peran yang dipersiapkan oleh dosen atau instruktur berupa skenario pembelajaran. Skenario pembelajaran ini memiliki indikator berupa ketercapaian kompetensi serta kemampuan kerjasama tim bagi taruna tingkat II semester tiga Prodi Studi Nautika Sekolah Tinggi Maritim Yogyakarta dalam pembelajaran kecakapan bahari II di media Mooring and Windlass milik Sekolah Tinggi Maritim Yogyakarta. Hasil yang dicapai terbentuknya tenaga kerja yang profesional khususnya kemampuan kerjasama tim khususnya departemen deck dibidang pelayaran khususnya Prodi Studi Nautika.
\end{abstract}

Kata Kunci: kerjasama tim, Mooring and Windlass

\begin{abstract}
The implementation of role-playing learning in the installation of peranca is a contextual learning model in the process of knowledge transfer to achieve the competence of cadets at the Yogyakarta Maritime High School or Stimaryo as prospective workers on board. Leadership and teamwork are carried out in the mooring and windlass anchor machine model belonging to Stimaryo in the Nautical Studies Study Program. The purpose of this paper is classroom action research in the process of attainment in the form of completeness in achieving minimum competency or completeness criteria of at least 75. The second marine skills learning method uses the role play method or role play prepared by the lecturer or instructor in the form of learning scenarios. This learning scenario has indicators in the form of competency achievement and teamwork ability for cadets level II in the third semester of the Nautical Studies Study Program at the Yogyakarta Maritime College in learning Marine Skills II in the Mooring and Windlass media belonging to the Yogyakarta Maritime College. The results achieved are the formation of a professional workforce, especially the ability of
\end{abstract}


team collaboration, especially the deck department in the shipping sector, especially the Nautical Studies Study Program.

Keywords: Teamwork, Mooring and Windlass

\section{PENDAHULUAN}

Kemampuan seorang pemimpin tidaklah didasarkan kepada sebatas pengetahuan secara teori saja tentang bagaimana cara memimpin, tetapi dapat di bekali seorang peserta didik untuk melakukan secara bermain peran. Dalam pembelajaran diperlukan strategi mentransfer ilmu bermain peran yang dilakukan peserta didik untuk mendapatkan aspek kognitif, afektif dan psikomotorik, sekaligus mendapatkan gambaran nantinya di lapangan usaha atau dunia industri. Pengendalian diartikan sebagai upaya untuk memastikan bahwa segala sesuatu aktivitas dan sumber daya yang telah direncanakan berjalan sesuai dengan ketetapan. Dalam aktivitasnya merupakan suatu usaha membandingkan sasaran yang ditetapkan dengan realisasi pelaksanaan untuk mencapai sasaran tersebut.

Kecakapan pelaut didefinisikan sebagai kemampuan pelaut dalam melakukan tugas dan kewajiban secara sigap, cermat, terkontrol, dan tepat guna dikapal untuk mencapai hasil seefisien mungkin serta mengarah ke keterampilan

\section{KAJIAN LITERATUR}

Pemimpin pelayaran yang dapat memberikan pemahaman yang utuh terhadap tugas dan fungsi kepada jajarannya dalam kegiatan pelayaran, kemudian memberikan kesempatan kepada jajarannya untuk menyampaikan pandangannya, pendapat, usulan dan saran serta melaksanakan dengan rasa tanggung jawab yang besar. Semua itu menggambarkan terlaksananya asas kebersamaan atau demokrasi untuk mencapai tujuan yang telah direncanakan.

Tim adalah sekelompok kerja dengan kemampuan, talenta, pengalaman dan latar belakang yang berbeda yang berkumpul bersama-sama untuk mencapai satu tujuan. Tim harus memiliki tujuan bersama yang jelas.

Beberapa kiat membangun tim yang baik yaitu:

1. Bergerak kearah yang sama secara bersama-sama

2. Perjelas keahlian dan tanggung jawab anggota tim, mengetahui cara melaksanakan tugas teknis mereka

Setiap kegiatan yang dilakukan oleh seseorang atau sebuah lembaga tentu mempunyai tujuan dan untuk mencapai tujuan tersebut perlulah dibuat perencanaan terlebih dahulu. Secara garis besar, perencanaan ini menggambarkan; apa, bagaimana, mengapa dan kapan akan dilakukan. Langkah-langkah penyusunan perencanaan.

Aram aram digunakan sebagai tempat duduk awak kapal yang sedang mengecat tiang kapal atau mengecat temberang kanan dan kiri. Alat ini dikaitkan pada tali yang disisipkan pada kerek yang ditempatkan di puncak tiang, ujung lainnya diikatkan diatas deck dan dijaga oleh seorang kelasi. Cara mencatnya dari atas kebawah. 
Peranca digunakan sebagai tempat berdirinya awak kapal yang sedang mengecat area pada lambung kapal atau haluan kapal. Cara membuatnya ikatan ujung tali yang digunakan pada roling kapal lalu ikat dengan menggunakan sosok pangkal dan sosok sesar. Ikatan ini dibuat agar kuat dan mudah dilepas setelah selesai pekerjaannya. Selain itu ikatan ujung tali yang berada pada peranca dengan sosok tiang. Ada beberapa macam bentuk tali yang berada dibelakang papan peranca misal bentuk N, X, IX, XI, Z dan lain lain.

Peranca menurut KBBI adalah batangan kayu, bambu, atau pipa besi yang disambung-sambung keatas dan kesamping untuk memanjat bangunan bertingkat. Peranca menurut Wikipedia adalah struktur sementara yang digunakan untuk menyangga manusia atau material dalam konstruksi atau perbaikan gedung dan bangunan-bangunan besar lainnya.

Dari dua definisi di atas dapat disimpulkan:

1. Bahan peranca bisa kayu, bambu, atau batangan pipa besi.

2. Peranca adalah penyangga atau penopang untuk bekerja di ketinggian.

Berdasarkan bahan peranca maka Peranca dengan bambu sering terlihat dalam pengerjaan konstruksi bangunan bertingkat. Biayanya relatif lebih murah. Tetapi punya beberapa kekurangan, antara lain:

1. Memerlukan waktu lama merakitnya

2. Tidak praktis untuk dibongkar pasang

3. Gampang rusak/lapuk karena panas dan hujan

Peranca yang lebih maju, dengan konstruksi batang-batang pipa, ditemukan misalnya pada saat kapal docking. Peranca dipasang oleh 10-15 orang pekerja dock yang khusus mengerjakan itu. Ruang gerak di peranca ini tentu lebih luas.



Gambar 1. Pemasangan Peranca

Sumber:https://www.kamuspelaut.com/2020/04/apa-arti-perancah.html

Peranca ini praktis, mudah dipasang bongkar. Komponennya mudah dikelompokkan. Dengan ukuran yang standar, mudah diganti jika rusak. Pada peranca bambu, batang-batang bambu vertikal, horizontal dan diagonal diikat dengan kawat. Sedang pada peranca pipa dijepit dengan brace. 


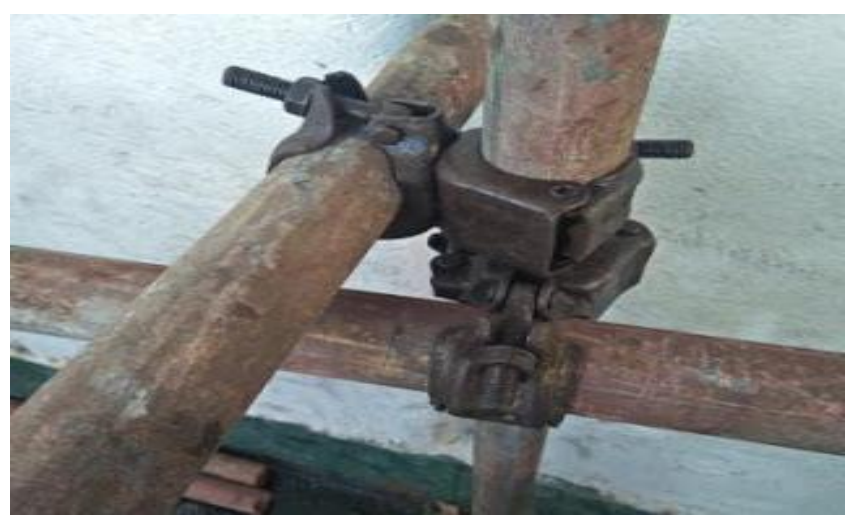

Gambar 2. Brace

Sumber:https://www.kamuspelaut.com/2020/04/apa-arti-perancah.html

Untuk pemakaian rutin, seyogyanya perancah dicek secara berkala. Sebelum dirakit, wajib dipastikan bahwa semua komponen dalam keadaan baik, aman digunakan.

\section{METODE PENELITIAN}

Jenis penelitian berupa kualitatif berisi deskripsi penelitian tindakan kelas yang dilakukan pada Tahun Akademik 2019/2020. Jenis penelitian tindakan kelas dalam rangka melakukan perbaikan terhadap kegiatan perkuliahan (Astriawati \& Wibowo, 2019). Penelitian tindakan kelas Adapun tempat pelaksanaan di Windlass and Moorings Model milik Sekolah Tinggi Maritim Yogyakarta yang beralamat di Jl. Magelang KM. 4,4 dusun Mesan Sinduadi Mlati Sleman Yogyakarta 55284. Target atau sasaran berupa ketercapaian kompetensi kemampuan kognitif, afektif serta psikomotorik persiapan pemasangan papan peranca sebelum pelaksanaan chipping dengan menggunakan Penilaian Ketepatan dalam pengerjaanya.

Metode Penelitian yang digunakan selain metode pustaka juga dilakukan dengan observasi penelitian tindakan kelas pada pembelajaran Kecakapan Bahari II, sedangkan untuk waktu pelaksanaan pembelajaran pada Prodi Studi Nautika Stimaryo Semester 3.

\section{PEMBAHASAN}

\section{A. Persiapan Pembelajaran}

Pelaksanaan pembelajaran persiapan chipping diawali dengan menyiapkan alat dan bahan yang sudah ditetapkan dalam skenario pembelajaran. Adapun skenario pembelajaran mengacu pada kompetensi apa yang harus dicapai yang tercakup pada indikator. Hal yang perlu diperhatikan sebelum menggunakan peranca. Beban yang diterima peranca harus merata untuk mencegah bahaya dan menjaga keseimbangan.

Dalam penggunaan peranca harus dijaga agar beban tidak melebihi kapasitas yang ditentukan. Peranca tidak boleh dipakai untuk menyimpan bahan kecuali segera dipakai. Tenaga kerja tidak boleh bekerja di dekat bangunan 
peranca sewaktu ada angin kencang. Untuk mencegah kerusakan bahan perancah harus dipasang dengan hati-hati. Peranca harus diberi lantai papan yang kuat dan rapat sehingga dapat menahan dengan aman tenaga kerja, peralatan dan bahan yang dipergunakan. Lantai kerja harus diberi pagar pengaman, apabila tingginya lebih dari 2 meter.

Upaya pencegahan kecelakaan yaitu:

a. Gunakan peranca yang sudah diperiksa sesuai pemasangan label tanda aman seperti :

1) Hijau : sepenuhnya aman

2) Kuning : aman dengan syarat gunakan sabuk pengaman, artinya kurang aman

3) Merah : tidak aman, artinya peranca dilarang dipakai

b. Mengikat material untuk mencegah jatuh.

c. Batasi jumlah beban untuk mencegah beban / muatan jatuh dari platform.

d. Dilarang meletakkan material atau membiasakan berserakan pada struktur bangunan.

e. Ikatlah peralatan ke pinggang atau tubuh untuk mencegah jatuh pada saat yang tidak terduga.

f. Rapatkan celah papan platform untuk mencegah alat dan material jatuh ke bawah.

g. Pinggirkan peralatan kerja untuk menghindari benturan di lantai kerja peranca.

h. Tempat untuk menahan kaki perancah (base plate) harus kuat untuk menghindari bahaya amblas (terbenam dalam tanah).

i. Gunakan papan alas dan dongkrak peranca untuk menyangga peranca

j. Ikatkan peranca yang tinggi pada struktur bangunan untuk keseimbangan

k. Sambungkan rangka peranca menjadi satu dan pastikan bahwa klemnya cukup kuat dan ikatlah untuk mencegah peranca ambruk.

Penggunaan peranca yang aman dan memenuhi persyaratan:

1. Material peranca harus kuat

2. Pondasi harus kuat dan stabil

3. Struktur peranca harus kuat dan stabil

4. Lantai kerja harus kuat dan aman

5. Scaffolder / pekerja mentaati standar K3

6. Lingkungan kerja bersih dan rapi

7. Beban sesuai kapasitas peranca

8. Akses naik/turun dengan tangga yang kuat dan stabil

Harus cukup kuat mendukung beban dan tekanan suatu proses kerja Peranca berbahan Pipa Logam

1. Dibuat dari bahan yang baik, cukup kuat menahan beban.

2. Pipa harus lurus, tidak berubah bentuk.

3. Pipa harus bebas karat.

Peranca berbahan kayu:

1. Kayu harus lurus, padat tak bermata kayu besar

2. Kering, tidak membusuk.

3. Mempunyai urat yang lurus. 
4. Usia kayu sudah cukup tua.

Konstruksi peranca terdiri dari komponen utama struktur peranca:

1. Batang vertikal,

2. Batang membujur,

3. Batang melintang, dan

4. Batang palang penguat Untuk menyatukan komponen utama, diperlukan asesori pendukung seperti:

a) Penyambung dan Pengunci (join pin, tali)

b) Pengikat / Penahan (clamp, swivel, ties)

Papan atau plat besi lantai kerja harus kuat dan rapat sehingga dapat menahan dengan aman pekerja, peralatan dan bahan yang digunakan. Lantai kerja harus diberi pagar pengaman apabila tingginya lebih dari $2 \mathrm{~m}$. Tenaga kerja menuju lantai kerja harus melalui tangga peranca. Hal yang harus diperhatikan pekerja yaitu harus selalu menggunakan Safety Belt, Safety Harness, sepatu keselamatan kerja, topi keselamatan dan sarung tangan.

Alat pelindung diri harus sesuai, berfungsi menurut standar yang dikeluarkan oleh pabriknya. Memenuhi dan mentaati semua syarat K3 peranca yang diwajibkan. Lingkungan.

Strategi pemakaian tangga peranca yang aman:

1. Usahakan sewaktu menurunkan/menaikkan tangga dari arah bawah dan pastikan bahwa tangga peranca yang ditempatkan telah terikat baik, sebelum mulai memanjat.

2. Pastikan bahwa sepatu atau alas kaki bebas lumpur atau gemuk sebelum mulai memanjat tangga peranca.

3. Jika memungkinkan tempatkan peralatan atau barang yang dibutuhkan di dalam kantong atau di dalam tas sewaktu memanjat tangga peranca sehingga kedua tangan dalam keadaan bebas dan dapat digunakan untuk berpegang.

4. Usahakan sewaktu membawa barang tidak bertumpu pada tangga atau gunakan alat pengangkat.

5. Sebagian besar kecelakaan disebabkan karena ketidak seimbangan atau memaksa menjangkau jarak yang terjauh.

6. Janganlah menjulurkan badan terlalu jauh dari tangga.

Cara yang terbaik adalah memindahkan tangga pada posisi aman yaitu Alat Pelindung Diri (APD) Bekerja di Ketinggian, Pelindung Kepala (Safety Helmet), Pelindung Kaki (Safety Shoes),Pelindung Tangan (Gloves), Baju kerja (pelindung radiasi sinar matahari), Sabuk Penyelamat (Safety Belt) untuk bekerja dengan pergerakan mendatar pada ketinggian serta Full Body Harness untuk bekerja dengan pergerakan vertikal pada ketinggian.

Disain peranca memiliki prinsip dengan memperhatikan kekuatan stabilitas dan kekuatan struktur penopang. Perhatian lainnya terkait keselamatan orang yang memasang maupun membongkar peranca disamping keselamatan orang yang menggunakan peranca. Selain itu juga perlu diperhatikan orang di sekitar peranca.

Prinsip design Peranca dimana dalam mendesign peranca perlu diperhatikan terkait dengan:

1. Kekuatan, stabilitas dan kekuatan struktur penopang 
2. Penampang peranca secara normal

3. Keselamatan orang yang memasang maupun membongkar

4. Keselamatan orang yang menggunakan peranca

5. Keselamatan orang yang ada disekitar peranca

Sebab terjadinya kecelakaan jika salah menggunakan peranca biasanya kecelakaan peranca yang sering terjadi :

1. Pekerja jatuh dari tempat tinggi.

2. Material dan alat jatuh mengenai pekerja lain di sekitarnya

3. Peranca yang kurang aman jatuh menimpa pekerja dan orang lain di sekitarnya.

4. Pekerja terjatuh pada saat naik/turun peranca.

5. Terpeleset atau tergelincir.

6. Kelebihan beban atau beban terkonsentrasi menumpuk di satu titik, yang mengakibatkan robohnya peranca.

\section{B. Persiapan Pemasangan}

Pada persiapan kerjanya dimana tim kelompok kerja mempersiapkan alat dan bahan yang akan digunakan pada pemasangan peranca. Adapun alat dan bahan yang di gunakan yang dipersiapkan taruna dalam kelompok kerja berupa; papan peranca, papan joli joli, tali pollipropelyne. Dalam hal ini alat dan bahan tersebut tersedia di Laboratorium Kecakapan Bahari sebagai salah satu fasilitas dari Sekolah Tinggi Mariitim Yogyakarta.

Dengan diawali Dosen membuat skenario pembelajaran dengan menentukan indikator akhir target kompetensi yang dimilki peserta didik setelah pembelajaran Adapun indikator yang ditetapkan sebagai tujuan pembelajaran yaitu para peserta didik mampu memasang peranca dan joli-joli sebagai dudukan kerja chipping pada dinding lambung kapal pada model windlass dan dinding petikemas sebagai model pembelajaran.

Implementasi pelaksanaan pemasangan peranca dan joli-joli, peserta didik menyiapkan peralatan pada railing haluan kapal pada model windlass Stimaryo. Adapun bahan yang diperlukan berupa tali polipropelyne dengan panjang 20 meter dengan diameter $6 \mathrm{~mm}$. Satu papan peranca dan satu papan joli joli.

\section{Organising}

Kelompok kerja yang di bentuk terdiri dari tiga orang taruna yang terdiri dari satu taruna sebagai koordinator dan dua orang taruna sebagai anggota. Adapun koordinator sebagai kepala kerja bertugas mengatur anggotanya dalam kerjasama tim dalam pemasangan peranca. Setelah itu dilakukan pembekalan keterampilan dalam proses pemasangan papan peranca dan papan joli-joli.

Membentuk kelompok kerja dengan cara membagi kelompok peserta didik dengan menunjuk nama yang memiliki urutuan pertama sebagai koordinator kelompok kerja.

\section{Actuating}

Koordinasi yang dilakukan pimpinan kelompok kerja dalam hal ini dilakukan secara bergantian agar kompetensi bisa didapatkan peserta didik. Adapun tahapan proses pelatihan atau pembelajaran kompetensi persiapan sebelum proses chipping. 
Sebagai tahapan pelaksanaan maka dilakukan pembagian pendalaman materi dalam menargetkan ketercapaian kompetensi minimum dalam hal kemampuan memasang tali pada peranca dan joli joli. Selanjutnya pemasangan tali pada reling kapal dengan menggunakan teknik simpul dan ikatan tali temali. Implementasi pengajar sebagai fasilitasi dan pendampingan memberikan pembekalan keterampilan dalam pembuatan simpul sosok pengikat, sosok tiang, sosok sesar.

Dalam proses pemasangan peranca dilakukan oleh tim kelompok taruna yang terdiri dari tiga taruna yang dikepalai oleh seorang ketua tim koordinator. Koordinator disini mempunyai peran mengarahkan proses pemasangan peranca dan joli joli dengan bekerjasama dua anggota lainnya secara berkelompok atau tim. Pemasangan tersebut dilakukan setelah mendapat order kerja chipping berdasarkan skenario pembelajaran yang sudah di tetapkan dalam persiapan kerja pada proses pemasangan peranca atau joli - joli.

Proses pemasangan tali pada papan peranca dimana peserta didik dalam proses pembelajaran mengalami langsung proses pemasangan tali peranca secara berkelompok bekerjasama secara tim dipimpin seorang koordinator kelompok . Adapun tahapan pertama yang dilakukan yaitu dalam proses persiapan yaitu taruna mengambil papan peranca dari Bosun's store di bawa ke Model Mooring and Windlass. Kemudian taruna meletakkan papan peranca dengan memberikan penyangga untuk kedua sisi papan peranca.

Langkah kedua memasangan tali polipropelyne dengan melingkarkan tali pada sisi dalam skor kayu usuk dilingkarkan ke bawah dengan menyilangkannya, lalu kedua ujung tali tersebut di tarik ke atas.

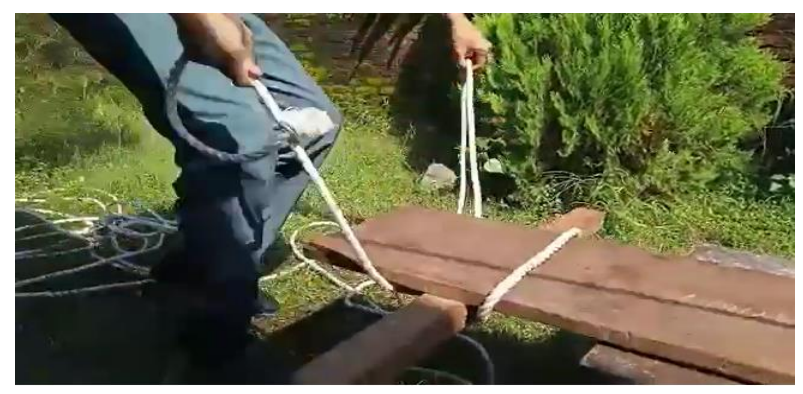

Gambar 3. Pengikatan tali pada papan peranca

Taruna Studi Nautika selain dibekali dengan gambar terkait dengan papan peranca juga dibekali dengan petunjuk pemasangan tali pada papan peranca. Pada proses pemasangan ikatan papan peranca pada ralling pagar haluan kapal model mooring and windlass Stimaryo dimana salah satu taruna mengikatkan ujung tali pada reling kapal model mooring dan windlass dengan menggunakan keterampilan ikatan sosok pengikat.

Langkah selanjutnya lingkaran tali diawal di masukkan ke dua ujung tali dengan menarik keatas. Sebagai tali pengikat ke railing kapal. Maksud dari ikatan ini agar kuat dan mudah dilepaskan setelah selesai pekerjaan. Ujung dari tali yang berada pada peranca oleh taruna diikatkan dengan sosok tiang. Untuk mengikat ujung tali dengan metode sosok sesar dengan kuat dan bila tali tersebut akan 
dilepas dapat dilepaskan dengan mudah dan cepat ikatan ini digunakan pada tali peranca yang diikatkan pada reling.



Gambar 4. Pengikatan tali pada raling



Gambar 5. Uji coba Penggunaan Papan peranca

Proses pemasangan kursi bootswain dengan cara kursi sudah diangkat cukup tinggi dengan orang yang akan mengerjakan maka dibuat dulu stopper dari tali penarik dengan tali jalannya. Dengan stopper ini akan cukup menahan beban sementara sosok dibuat. Dengan membuat goba yang cukup panjang dari tali penarik yang dilewatkan antara tali-tali pengikat kursi melewati kepala dan pundak orang yang duduk didalamnya dan diteruskan melalui belakang kaki sampai jatuh di depan orang itu. Bilamana tali penarik sudah berada didepan orang tersebut maka diambil slacknya dan stopper dibuka. Kursi monyet ini ada juga yang diturunkan dengan memasang ganjo pada tali jalan dan tali penarik disangkutkan, namun cara ini lebih beresiko.

Apabila kita akan mengecat lambung kapal, diperlukan alat peranca dan cara mengikat dengan metode beberapa macam, yang masing masing mempunyai keuntungan dan kerugiannya.

\section{E. Pencapaian Kompetensi}

Adapun standar Kriteria Ketuntasan Minimum yang ditetapkan untuk kelompok yaitu 75.

Kriteria Grade yang di gunakan yaitu:

Grade Nilai Deskripsi

A 90-100 Pengerjaan dilakukan dengan tepat dan sesuai dengan kenyataan serta sesuai dengan waktu penyelesaian 


$\begin{array}{lll}\text { B } & 80-89 & \begin{array}{l}\text { Pengerjaan dilakukan dengan tepat tetapi } \\ \text { penggunaan waktu penyelesaian kurang efisien }\end{array} \\ \text { C } & 60-79 & \begin{array}{l}\text { Pengerjaan dilakukan sampai selesai tetapi } \\ \text { ketepatan kurang dan waktu yang digunakan tidak } \\ \text { efisien }\end{array} \\ \text { D } & <60 & \text { Pengerjaan tidak selesai }\end{array}$

Strategi pencapaian KKM yang harus di capai peserta didik dengan kerjasama tim dengan nilai 75 dilakukan berulang kali, bila belum mencapai nilai tersebut. Fasilitasi dan pendampingan harus dilakukan dengan baik agar ketercapaian kompetensi atau kecakapan pelaut dapat dimiliki peserta didik.

Implementasi pada pencapaian KKM dilakukan dengan memantau kerjasama tim berupa kemampuan komunikator dan komunikan. Kemampuan ketua kelompok dalam mendata alat dan bahan merupakan langkah awal yang dikerjakan, begitu juga dengan kemampuan ketua kelompok dalam mengkoordinir anggotanya dalam pemasangan peranca berupa pemahaman serta pengetahuan simpul dan ikatan. Strategi yang utama adalah pembiasaan dengan latihan membuat simpul dan ikatan agar dari pembiasaan itu peserta didik tidak hanya tahu melainkan mampu mengerjakan atau membuatnya. Adapun kendala pada saat pembelajaran kelompok pada proses pemasangan papan peranca adalah: kurang terampil dalam pemahaman jenis simpul, kurang terampil dalam pemahaman jenis ikatan, masih kaku dalam membagi tugas anggota kelompok.

\section{PENUTUP}

\section{Kesimpulan}

1. Pelaksanaan pembelajaran persiapan chipping diawali dengan menyiapkan alat dan bahan yang sudah ditetapkan dalam skenario pembelajaran. Adapun scenario pembelajaran mengacu pada kompetensi apa yang harus dicapai yang tercakup pada indikator.

2. Koordinasi yang dilakukan pimpinan kelompok kerja dalam hal ini dilakukan secara bergantian agar kompetensi bisa didapatkan peserta didik. Adapun tahapan proses pelatihan atau pembelajaran kompetensi persiapan sebelum proses chipping.

3. Proses pemasangan peranca dilakukan oleh tim kelompok taruna yang terdiri dari tiga taruna yang dikepalai oleh seorang ketua tim koordinator dalam mengarahkan proses pemasangan peranca dan joli joli. Pemasangan tersebut setelah mendapat order kerja chipping untuk persiapan kerja dengan memasang peranca atau joli - joli.

4. Proses pemasanga tali propelyne memerlukan suatu kerjasama antara koordinator dengan anak buah.

\section{DAFTAR PUSTAKA}

Astriawati, N., \& Wibowo, W. (2019). Peningkatan Motivasi Dan Hasil Belajar Taruna Melalui Media Berbasis "Whiteboard Animation” Bidang Navigasi 
Pelayaran. Prosiding Konferensi Nasional Penelitian Dan Pembelajarannya IV, $\mathrm{p}-28$.

Basu Swasta 1988 dan Ibnu S, W Pengantar bisnis modern, Liberty Yogyakarta, edisi ke 3.

BPLP (tanpa tahun) Semarang, Tali temali, BPLP, Semarang

Soleh Haryono dan Amrinul , 2010, Djangkar, Kecakapan Bahari sesuai dengan

IMO Model Course 7.03-7.04 STCW 2010.

Tim BPLP, (tanpa tahun) Perlengkapa Kapal untuk perwira kapal niaga, BPLP, Semarang

Kemenhub Badan Pengembangan SDM Perhubungan Pusat pengembangan SDM 2016 Perhubla Balai Pendidikan dan pelatihan Pelayaran Padang Pariaman. Tim Penyusun Balai Diklat Pelayaran Padang Pariaman, Perlengkapan Kapal, Padang.

Williem Nikson Sitompul dkk, 2019, Leadership dan Teamwork dalam pelayaran. Djangkar, Jakarta,

Willem Nikson S, Vidya Selasdini, dan Capten Susetyo Widayat H,Leadership dan teamwork dalam pelayaran, Djangkar, Jakarta

https://www.kamuspelaut.com/2020/04/apa-arti-perancah.html

https://simantu.pu.go.id/epel/edok/dc539_Bahan_Tayang_K3_Pemakaian_Tangga Perancah_SIO.pdf

https://www.youtube.com/watch?v=p0VfiT4E8lc 